\title{
CASAS DE FARINHA: REFLEXÕES ACERCA DO TRABALHO E EDUCAÇÃO EM COMUNIDADES TRADICIONAIS DO INTERIOR DA BAHIA
}

\author{
CASSAVA FLOUR MANUFACTURERS (CASAS DE FARINHA): REFLECTIONS ON \\ WORK AND EDUCATION IN TRADITIONAL COMMUNITIES OF THE INTERIOR \\ OF BAHIA, BRAZIL
}

\section{M.O. SANTOS ${ }^{1,{ }^{*},}$ U.T. AMARAL ${ }^{2}$, A.E.S. ALVES ${ }^{3}$ e M.N.CAVALCANTI JUNIOR ${ }^{4}$}

1 Universidade Estadual do Sudoeste da Bahia, Doutoranda Programa de Pós-Graduação em Memória Linguagem e Sociedade, Membro do Grupo de Estudos História, Trabalho e Educação Brasil

2 Universidade Estadual do Sudoeste da Bahia / Museu Pedagógico - Brasil

${ }^{3}$ Universidade Estadual do Sudoeste da Bahia, Programa de Pós-Graduação em Memória Linguagem e Sociedade, Coordenadora do Grupo de Estudos História, Trabalho e Educação do Museu Pedagógico da UESB - Brasil

${ }^{4}$ Instituto Federal da Bahia - Campus Vitória da Conquista (BA)

\section{ARTICLE INFO}

Article history:

Received 2018-07-02

Accepted 2018-08-17

Available online 2018-08-31
Palavras-chave: Trabalho. Educação. Casa de Farinha.

Keywords: Labor. Education. Cassava Flour Manufacturers.

${ }^{*}$ Autor correspondente:

E-mail: momarisa@gmail.com

RESUMO. O presente estudo tem como objetivo descrever a memória das relações entre trabalho e educação no processo de construção de experiências educativas nas Casas de Farinha em comunidades tradicionais do interior da Bahia. Para tanto, intencionou-se, a priori, na evocação de registros históricos, passando sequencialmente para a contextualização e caracterização de três localidades tradicionais na fabricação da farinha no interior da Bahia: comunidade de Campinhos e Simão e povoado de Itaipu. As análises foram realizadas por meio de entrevistas. Pontuou-se, a memória materializada nas narrativas dos moradores, ressaltando elementos que referendam a relação entre a educação e o trabalho como base de convergência entre a prática laboral e experiências educativas. Os fundamentos teóricos, como Cascudo (1983); Saviani (2007); Pedroza (2014); Simmel (2006), dentre outros, respaldaram a discussão preterida. Ao término, verificou-se que as Casas de Farinha veiculam a farinhada além do seu processo produtivo, sendo possivel discutir elementos como divisão sexual do trabalho, sociabilidade familiar na produção, a relação homem e natureza e o trabalho como fonte precípua de construção de experiências educativas. 
ABSTRACT. This research aims to describe the memory of the relationship between work and education in the process of constructing educational experiences in cassava flour manufacturers (Casas de Farinha) in traditional communities in the interior of Bahia. It was intended to evocation of historical records, passing sequentially to the contextualisation and characterization of three traditional localities in the manufacture of flour in the interior of Bahia: Campinhos and Simão communitiesand Itaipu village. The analyzes were performed through interviews. It was described the materialized memory in the narratives of the inhabitant, emphasizing elements that refer to the education and work relationship as a basis for convergence between work practice and educational experiences. The theoretical foundations of the Cascudo (1983); Saviani (2007); Pedroza (2014); Simmel (2006), among others, supported this discussion. Finally, it was verified that the cassava flour manufacturers convey the production of the flour besides its productive process, being possible to discuss elements such as the sexual division of labor, family sociability in the production, the relationship being human and nature and the work as the primary source of construction of educational experiences.

\section{Introdução e procedimentos metodológicos}

O presente estudo tem como objetivo descrever a memória das relações entre trabalho e educação no processo de construção de experiências educativas nas Casas de Farinha em comunidades tradicionais do interior da Bahia. As análises são resultados de pesquisas desenvolvidas nas comunidades de Campinhos e Simão, em 2007 (SANTOS, 2007), no povoado de Itaipu, em 2016 (AMARAL, 2006), localidades situadas no município de Vitória da Conquista, BA; como também, da realização da exposição imagética "Casas de Farinha", em 2017 (ALVES, CAVALCANTI JR, SANTOS E AMARAL, 2017). Este texto organizou-se em quatro partes, a saber: a primeira apresenta o objetivo e os procedimentos metodológicos; a segunda contempla registros históricos da produção da farinha no Brasil no período colonial; a terceira permite a apresentação das comunidades tradicionais estudadas, traçado por meio dos relatos das memórias de moradores, a relação entre o trabalho e a educação no processo produtivo realizado nas farinheiras das comunidades tradicionais. Por último, seguem as considerações finais, que revisitam o texto e apontam para a apreciação e análise na perspectiva do estudo e de suas contribuições.

Pelo caráter social da pesquisa e de seus vieses objetivos e subjetivos, reitera-se como fonte metodológica os procedimentos marcados pela pesquisa qualitativa, a qual considera, segundo Minayo (1994, p. 22) o "[...] mundo dos significados das ações e relações humanas", vez que os processos não são compreendidos desconectados dos contextos histórico, político, econômico e social em que estão inseridos, apoiando-se no suporte da pesquisa bibliográfica que sustenta a discussão teórica e como instrumento empírico utili- 
zou-se da entrevista como acervo de memórias, fazendo sua eminente relação entre o trabalho e a educação nas farinheiras.

\section{Fundamentação}

\subsection{A história das Casas de farinha no período colonial do Brasil}

Inútil pensar que o alimento contenha apenas os elementos indispensáveis à nutrição. Contém substâncias imponderáveis e decisivas para o espírito, alegria, disposição criadora, bom humor. (CASCUDO, 1983c, p. 405).

Um dos grandes desafios dos portugueses ao iniciar o processo de colonização na América foi a adaptação alimentar. Nas novas terras, eles não teriam como reproduzir o que cultivavam na Europa e a importação pura e simples de seus gêneros alimentícios não seria tarefa fácil para saciar todos os colonos, teriam, portanto, que se adaptarem àquilo que a colônia oferecia.

Na sua carta ao rei D. Manoel sobre o "achamento" do Brasil, Pero Vaz de Caminha (TUFANO, 1999, p. 49) chamou a atenção sobre um "inhame" que os índios comiam bastante e que indicava ser a base de sua alimentação. Na verdade, ele estava fazendo referência à mandioca, a planta nativa que melhor se adaptaria à agricultura portuguesa e que se tornaria a base alimentar da colônia, ao lado do milho e do feijão. A mandioca é um tubérculo cuja raiz é importante reserva de amido. Segundo Cascudo (s.d.), seu significado em tupi é "casa de Mani" (mani (branco) + oca (morada)). Sua origem é do continente americano, provavelmente da Amazônia. É uma planta tipicamente brasileira: das mais de cem espécies, oitenta são nativas do Brasil. Para o colono português a mandioca possuía grandes vantagens: não necessita de terras férteis, nem de chuva regular ou adubação; seu rendimento aumentava até mesmo em terras mais secas. Era de fácil manejo e não precisava de sementes, sendo reproduzida pelas ramas, chamadas de maniba ou maniva. Era bastante resistente às doenças, possuindo um ciclo vegetativo que variava de seis meses a três anos, podendo ser colhida a qualquer tempo ou deixada na terra, sem apodrecer.

Dos seus subprodutos, a farinha foi a que mais fez sucesso e marcou a culinária colonial. Cascudo (s.d.) a chamou de "rainha da mesa", apontando para a sua importância na alimentação popular. Chegou a ser difundida em Portugal, para quem os portugueses recorriam em época de escassez de trigo. Todos os estratos sociais da colônia a consumiam, desde os mais altos até os escravos. Por ano, uma pessoa consumia cerca de 300 litros de farinha. Suas boas características a levaram ao porte de moeda de troca no comércio de escravos africanos.

Havia dois tipos de farinha: a de guerra era muito seca e torrada, durando mais de um ano sem estragar, qualidade que a tornava a preferida para a alimentação das tripula- 
ções dos navios portugueses. O segundo tipo era a farinha fresca, mais delicada e de meIhor sabor, mas que durava apenas dois ou três dias antes de estragar.

Os portugueses aprenderam a fazer a farinha com os índios, ou melhor dizendo, com as índias, uma vez que sua produção era uma atividade tipicamente feminina. $O$ francês Jean de Léry, membro da aventura galesa da França Antártica no Brasil, relatou em 1557:

Depois de arrancá-las, as mulheres [...] secam-nas ao fogo no [bucan...] ou então as ralam ainda frescas sobre uma prancha de madeira, cravejada de pedrinhas pontudas [...]. Para preparar essa farinha usam as mulheres brasileiras grandes e amplas frigideiras de barro, com a capacidade de mais de um alqueire e que elas mesmas fabricam com muito jeito, põem-na no fogo com certa porção de farinha dentro e não cessam de mexê-la [...] até que a farinha assim cozida tome a forma de granizos e confeitos. (PEDROZA, 2014)

Dez anos depois, em 1587, o português Gabriel Soares de Sousa relatou o que viu entre os índios tupinambás de Sergipe:

(...) para se aproveitarem os índios e mais gente destas raízes, depois de arrancadas rapam-nas muito bem até ficarem alvíssimas, o que fazem com cascas de ostras, e depois de lavadas ralam-nas em uma pedra ou ralo, que para isso têm, e, depois de bem raladas, espremem esta massa em um engenho de palma, a que chamam tapeti, que lhe faz lançar a água que tem toda fora, e fica essa massa toda muito enxuta, da qual se faz a farinha que se come, (...) muito doce e saborosa. (...) E para fazer a farinha destas raízes se lavam primeiro muito bem, e, depois, desfeitas a mão, se espremem no tapeti, cuja água não faz mal; depois de bem espremidas desmancham esta massa sobre uma urupema, que é como joeira, por onde se coa o meIhor, e ficam os caroços em cima e o pó que se coou lançam-no em um alguidar que está sobre o fogo, aonde se enxuga e coze da maneira que fica dito, e fica como cuscuz, a qual em quente e em fria é muito boa e assim no sabor como em ser sadia e de boa digestão. (PEDROZA, 2014)

A forte influência indígena no fabrico da farinha pode ser vista não somente nos nomes de instrumentos e produtos ou nas técnicas, mas também na organização do trabalho e na casa familiar como centro e modo de produção. As famílias mais pobres fabricavam a farinha à noite dentro de suas próprias cozinhas, onde ficavam a roda de ralar, a prensa e o forno. Nas terras onde houvesse mais espaço e melhores benfeitorias, surgiram as Casas de farinha. Ali o modo de se produzir a farinha não mudou muito em relação à maneira como as índias faziam e assim permaneceu por séculos. A mandioca era descascada manualmente pelas mulheres raspadeiras (entre 10 e 15), sentadas em círculo e cercadas por suas crianças. Depois de lavada, a mandioca era levada para a roda de ralar ou bolandeira. A cevadeira era a responsável por colocar a mandioca no caititu e de regular a pressão, enquanto dois homens davam impulso ao rolo. Depois de cevada a mandioca transforma-se numa massa úmida que é embalada em palhas e levada para uma prensa ou ao tipiti (rede de cerdas de buriti) para escorrer a manipueira (parte ruim da mani, em tupi), o sumo venenoso (ácido cianídrico). Essa massa prensada gerava torrões. Para serem peneirados os torrões, 
utilizavam-se as urupemas (grandes peneiras). A parte grossa, chamada de crueira, secava ao sol e serviria de ração para galinhas. A parte fina era lavada e torrada no forno a lenha, feito de adobe. A torrefação era tarefa de mulheres, que em duplas usavam grandes rodos de madeira para mexer a massa.

Do trabalho da Casa de farinha, saíam a base para o que se tornaria comum na mesa do brasileiro das mais diferentes regiões: além da farinha, o carimã (fécula ou povilho), a tapioca, a puba e os beijus. Da farinha, surgiriam pratos como a farofa branca, a de batatadoce, a de jerimum, o cuscuz de mandioca, o pirão de galinha, de ovo ou de peixe, a paçoca de carne-seca, a "papa" com que as mães sertanejas alimentavam os filhos, o remate (caldo de feijão engrossado com farinha), o bode (farinha, pedaço de rapadura e outro de carneseca) e até sobremesas (farinha misturada com melado da cana ou com frutas em calda).

Em Sergipe havia o costume de se entoar cantigas durante os trabalhos nas Casas de farinha. Eram chamadas de "aboios da farinhada" (PEDROZA, 2014).

Eu queria ser mandioca

De sutinga verdadeira

Pra andar de mão em mão

E no colo da cevadeira.

Adeus casa de farinha

Adeus banco de ralar mandioca

Adeus morena bonita

Que me dava tapioca.

\subsection{As Casas de farinha: Campinhos, Simão e povoado de Itaipu em Vitória da Con- quista - BA.}

"Os propósitos da história são variados. Mas um deles é o de prover aqueles que a leem de um sentido de identidade, de um sentido de sua origem" (Jim Sharpe)

Não tão distante do legado histórico brasileiro, mais especificamente no interior da Bahia, em Vitória da Conquista, em comunidades tradicionais, encontram-se espaços produtivos ou vestígios destes, que se aproximam muito das influências recebidas pelo Brasil no período colonial. Apenas, por dimensões didáticas e por estarem incluídas como fontes de pesquisa e estudo, usar-se-á como lócus para o presente artigo as comunidades tradicionais na produção de farinha Campinhos, Simão e o povoado de Itaipu.

As comunidades tradicionais serão aqui compreendidas como "grupos culturalmente diferenciados e que se reconhecem como tais, que possuem formas próprias de organização social, que ocupam e usam territórios e recursos naturais como condição para sua reprodução cultural, social, religiosa, ancestral e econômica, utilizando conhecimentos, inovações e práticas gerados e transmitidos por tradição", (BRASIL, DECRETO 6.040, ART. 3ำ § $\left.1^{\circ}\right)$. 
Considerada como metrópole regional, Vitória da Conquista, fundada desde 1840, possui uma extensão territorial de $3.204,257 \mathrm{~km}^{2}$, distanciando da capital baiana em cerca de 510 quilômetros, com população 348.718 habitantes, conforme Censo IBGE (2010).

Campinhos e Simão estão localizados no Sudoeste baiano, na cidade de Vitória da Conquista em regiões muito próximas e adjacentes, o que faz com que um referende o outro; possuem população equilibrada entre homens e mulheres e prevalência de jovens, conforme IBGE (2010).

Campinhos e Simão, considerados como bairro de Vitória da Conquista, em função da Lei Municipal n 1385; 2006, do Plano Diretor urbano de 26/12/2006-PDU em que fica estabelecido, a partir do mesmo, o reconhecimento público do bairro enquanto unidade integrante do território em questão, deixando de ser a partir da mesma data distrito do município. Segundo dados do IBGE (2010) a comunidade de Campinhos possui uma população de 4889 moradores, sendo 2484 homens e 2405 mulheres. Do universo populacional retira-se 487 crianças entre 0 a 4 anos, existem mais jovens do que idosos. Sendo a população composta de $31.5 \%$ de jovens e $4.9 \%$ de idosos.

Campinhos e Simão estiveram entre os maiores beneficiadores da mandioca na região, gerando empregos diretos, além dos indiretos em função da lavoura e comercialização dos produtos oriundos e derivados do referido tubérculo (SANTOS, 2007). Distanciado do centro da cidade em $9 \mathrm{~km}$ aproximados, os logradouros citados, por volta de 1946 - enquanto distritos do município de Vitória da Conquista começaram a se destacar em uma nova atividade econômica: Casa de farinha. Embora, hoje verifica-se um movimento de retração nesta prática produtiva neste espaço, por muito tempo ela foi referência e alimentou outras cadeias produtivas regionais.

A localização espaço-geográfica está pontuada por vias rodoviárias de suma importância: a BR 116, BA 262 e a BA 407, as duas primeiras permitem, pelo lado oeste da cidade, o acesso à capital baiana e ao sul do país ; e do Estado respectivamente; a terceira liga o município a várias cidades do sertão (Brumado, Guanambi, Caetité, Anagé) e ao oeste do Estado da Bahia.

O povoado de Itaipu, pertencente ao distrito de José Gonçalves, situado no Município de Vitória da Conquista- Bahia, localizado entre as cidades de Vitória da Conquista e Planalto. Itaipu está a $36 \mathrm{~km}$ da sede municipal e a $7 \mathrm{~km}$ da BR 116, e, pode também definir-se como uma comunidade rural, espaço onde vivem famílias numerosas, caracterizado por uma ruralidade explícita na paisagem.

As Casas de farinha definem não somente um espaço produtivo, mas um fenômeno de sociabilidade como forma natural de "sociação" fazendo uma analogia entre a realidade e o lúdico, ou seja, relaciona o concreto das interações sociais com o sentimento de 
satisfação derivadas da "sociação" entre indivíduos na forma de uma unidade, pois congratula vínculos parentais no processo de produção. A sociabilidade vem a ser o espaço onde a interação sai dos meandros formais e entra segundo Simmel (2006) no âmbito do jogo, da conversa "despretensiosa" como uma forma lúdica de sociação, pois para o autor, toda sociabilidade é um símbolo da vida, quando essa surge no fluxo das relações e interações entre seus envolvidos.

Fotografia 1 - Modelos de Casas de farinha

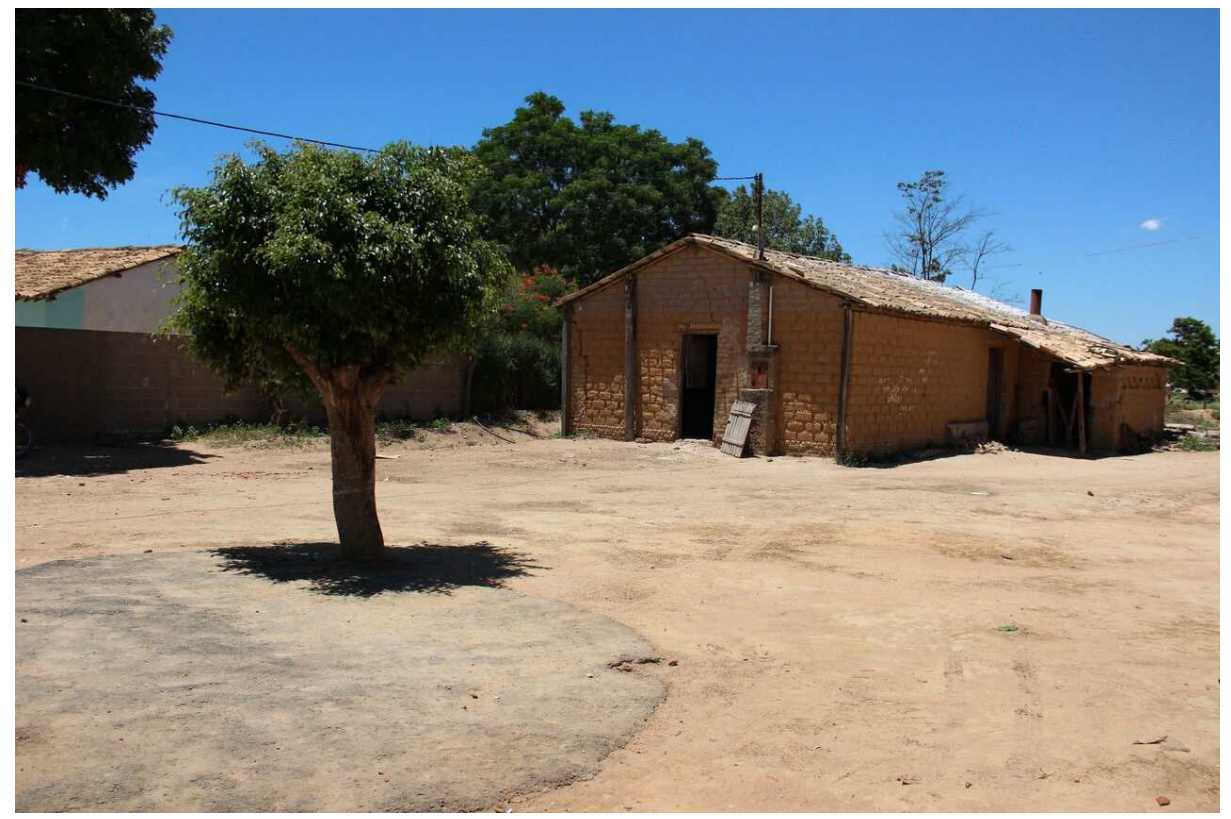

Fonte: Patrick Mendes Oliveira, acervo particular 2012

Compreende-se então que as Casas de farinha são estabelecimentos dedicados à produção da farinha de mandioca ou dos derivados desta, geralmente se referem a estabelecimentos de pequeno porte e sem maiores investimentos estruturais. É um espaço de vínculos e sociabilidade da vida, entendendo que o processo de produção garante a reprodução do grupo familiar. Aproxima os membros da família por meio da solidariedade e da colaboração, em que se produz um mundo de relações sociais permeadas por características adversas ao mundo capitalista formalizado, noção construída por Martins (2008, p.32). De acordo com essa ideia, as relações assumem um sentindo familiar e comunitário e os laços de solidariedade e de colaboração aproximam os laços familiares. Demarcam, além do espaço lúdico, o processo de socialização de saberes, o dialogo com as práticas, bem como as relações de gênero.

Nesse sentido, pela convergência de estudo de um espaço produtivo particular - as Casas de farinha - demonstram o trabalho e a educação como atividades especificamente humanas e permitem lembrar a definição do trabalho em seu sentido ontológico, no qual o 
homem além de racional, tem sua essência demarcada pelo trabalho, posto que ao agir sobre a natureza ele a transforma em função de suas próprias necessidade de adaptação ao meio. Essa essência não é uma dádiva divina ou natural, essa essência é um feito do próprio homem (SAVIANI, 2007). Contraditoriamente, essa relação também assume um caráter alienado, baseada na exploração social do trabalho do homem pelo próprio homem e na educação classista.

A produção da farinha é aqui entendida como este movimento natural do homem que ao se confrontar com a natureza e com os recursos dispendidos por ela, transforma e se transforma, modifica e também é modificado pelas relações naturais. Avançando nesse conceito e abarcando o par com a educação, compreende-se que os espaços de sociabilidade das farinheiras e de seus vínculos na produção remetem à importância e a transferência do saber de ofício no trabalho executado. Nesse sentido, observa-se uma aproximação do trabalho com o aprendizado do ofício e, com isso, o trabalho revela-se como uma dimensão educativa., "aprender trabalhar trabalhando", como ratifica Saviani (2007). Saber laboral como prática educativa socializada, a organização do espaço das Casas de farinha incorpora saberes e práticas educativas, que surgem das relações de convivência.

\footnotetext{
Tratam-se de saberes de experiência que foram adquiridos ou socializados nos fazeres cotidianos de homens e mulheres, que por serem sujeitos da práxis, constroem seus projetos de vida, resistem e "tecem representações sobre o mundo vivenciado" (OLIVEIRA, 2008, p.64)
}

Há que considerar que por ser uma atividade produtiva ainda permeada pelo modo de produção artesanal, ainda prevaleça a relação comunal, em que a vida das famílias é regida pela integração entre espaço de produção e funções domésticas; o trabalho domiciliar como extensão de um empreendimento (ALVES, 2013). A farinha não se apresenta apenas como um produto ou um item mais na mesa, ela também se faz marcante no linguajar, na memória e na identidade dos moradores e consumidores locais.

As Casas de farinha tanto no povoado de Itaipu, quanto em Campinhos e Simão ficavam nas propriedades pertencentes aos pequenos agricultores. A quantidade de Casas de farinha tem retraído nas duas regiões por razões diversas. Os pequenos agricultores, em sua maioria, possuíam suas próprias Casas de farinha, elas eram mais numerosas nessas comunidades tradicionais.

Campinhos, Simão e Itaipu contam com pequenos produtores, possuidores de uma base produtiva agroindustrial familiar, caracterizada, a priori, como atividade econômica responsável pela renda principal gerada na comunidade, essa é uma estratégia ou 
mecanismo de sobrevivência do grupo familiar alargada por muitos anos. Trabalhar ao redor da raiz da terra propiciava a sobrevivência cotidiana e garantia condições para que a família garantisse sua sobrevivência no núcleo familiar, conforme reforça o depoimento de um morador local.

[...] aqui a gente trabaiava tudo junto, era pouquinha a mandioca e a farinha, mas dava com dificuidade manter a família. Tive seis filhos, mais eu e a muié, conseguimos criar todos, criar bem ou mal, mas criamos, nem sempre conseguimos dá o de mió num é, mas nenhum lá em casa que "deu pra coisa ruim". Tá tudo casado e com suas famílias. (Entrevista realizada com proprietário de Casa de Farinha em Junho de 2006)

Ao analisar o trecho acima, o linguajar recorrente do trabalhador em depoimento, externa na memória os laços familiares recorrentes do processo produtivo, a valorização da família. O depoente, mesmo apontando as dificuldades com o labor e a vida, reconhece que conseguiu constituir uma família amparada em valores, e esses são o reflexo do trabalho empreendido, sem que houvesse dissociação entre o trabalho e a família. Ao término de sua narrativa, percebe-se que a continuidade da família é sim, um valor externado de satisfação, pois todos os seus filhos já estão "casados".

A produção, tanto em uma localidade como em outra, quando acionada, atende às solicitações mediadas pelo mercado regional, não há planificação precisa ou previamente elaborada, responde a uma demanda estimada ou de costume, como também visa o fornecimento de matéria-prima para outras cadeias produtivas da cidade e de municípios próximos à Região, como é o caso das fábricas de biscoitos. A fabricação ainda se assemelha aos modelos antigos de produção como já reforçado anteriormente, prevalecendo em todas as Casas de farinha, ainda em funcionamento, a ambiência artesanal e primária que vai do início da cadeia produtiva até o escoamento dos derivados para o consumo direto e indireto dos produtos e derivados.

A produção da farinha e outros derivados da mandioca são comercializados na sede de Vitória da Conquista (BA), na CEASA (Central de Abastecimento), assim como também vendem para terceiros (atravessadores), os quais levavam para outras regiões e cidades próximas ao entorno do sudoeste baiano e norte de Minas Gerais.

O modo de produção nas Casas de farinha do período colonial não se diferencia muito do trabalho nas farinheiras de Campinhos, Simão e do povoado de Itaipu situados na região de Vitória da Conquista - BA.

A tradição, entendida conforme a discussão permeada por Hobsbawm (2002), denota o conjunto de práticas, de natureza ritual ou simbólica, regulado por regras aceitas por todos, que tem como objetivo desenvolver na mente e na cultura determinados valores e normas de comportamento, por meio de uma relação com o passado feita pela repetição 
constante dessas práticas, somado ao processo de trabalho realizado nas Casas de farinha perduram nos dias atuais na memória dos grupos que habitam as comunidades de Campinhos e Simão e no povoado de Itaipu, ainda que em algumas delas não mais funcionem no seu espaço físico e são pretéritas. Para o referido autor, um dos aspectos mais fortes da tradição é sua característica invariável, ou seja, seria um conjunto de práticas fixas que, por serem sempre repetidas de uma mesma forma, remeteriam ao passado, real ou imaginado.

As memórias dos moradores, em suas narrativas, revelam a tradição do trabalho nas plantações de mandioca e na execução do trabalho delegado nas Casas de farinha, traduzindo significados importantes para esses grupos que mantêm essa memória viva. Tais relações construídas demonstram assim como ressalta Halbwachs (1990), os traços deixados pelo passado, em que são visíveis em alguns aspectos até mesmo pelo modo de pensar e sentir.

Vê-se que os sujeitos que se inserem no processo de trabalho nas Casas de Farinha não apenas guardam, mas produzem uma memória com o legado histórico das experiências educativas que acumulam ao realizarem suas diferentes atividades no processar da mandioca, ou de alguma maneira guardaram consigo lembranças pertinentes ao registro espacial e temporal. Nesse sentido, observa-se uma aproximação do trabalho com o aprendizado do ofício e, com isso, o trabalho revela uma dimensão educativa.

Em uma cadência própria e bem peculiar, o trabalho realizado nas Casas de farinha determina um traço coletivo em sua realização. No processo de fabricação da farinha, há uma forte presença de mulheres, principalmente, na raspagem da mandioca, e as atividades que exigem maior força física, como a prensagem, são desenvolvidas por homens. Isso denota as diferenciações entre o trabalho do homem e o trabalho da mulher, reforçando a divisão sexual do trabalho, em que tais atividades desenvolvidas na esfera doméstica e na esfera profissional são como uma extensão da casa, abrem caminho para se pensar na divisão do trabalho entre homens e mulheres como reflexo do modo de produção doméstico adotados nestes espaços produtivos, aqui especificamente das Casas de farinha, conforme vem sendo discutido por Hirata e Kergoart (2007).

A agilidade e presteza do trabalho feminino desempenha um papel de fundamental importância neste estágio no inicio da produção da chamada "farinhada". Sentadas em semicírculo, em pedras, no assoalho do chão batido ou em pequenos tamboretes e sem apoio nas costas, se dividem em capoteiras ou tiradeiras de capotes, ou seja, algumas raspam a "cabeça" ou o "capote" da mandioca até a metade - capoteiras - e repassam para outra que sequencialmente destituí o resto da raiz - tiradeiras de meia, no entanto, em qualquer estágio são denominadas, de forma generalizada de raspadeiras, sempre no 
feminino, porque os homens não participam desta atividade, lembrando em Cascudo (s.d.) a referência dada às índias no período colonial da nossa história.

É muito comum neste momento presenciar falácias entre o mulherio, conversando de maneira animada sobre assuntos pertinentes à comunidade; entre um tempo e outro, surgem ações alternativas como o cantarolar de músicas regionais, antigas ou conhecidas, nos remetendo aos "aboios da farinhada" remetido na primeira parte deste artigo (PEDROZA, 2014). Em média, as mulheres realizam este trabalho por 8 horas diárias, com pequenos intervalos para alimentação, lembrando que é facultado horários alternativos, em função da demanda, para homens e mulheres. Ao findar do dia, pelo ritmo e posição dos trabalhos oferecidos, é comum verificar a diminuição no ritmo das conversas, mas ainda sobressai, até o último instante, o tilintar das facas que ainda perseveram para terminar o trabalho finalizado na chamada "ruma de mandioca"; "monte de mandioca".

Sobre as funções desempenhadas por homens e mulheres na produção da farinha, Dona Clemência afirma:

la os home tamém, os home ia pra mexer a farinha, enxugar a massa, é assim, ..., prantava maniva, prantava feijão, milho, trabaiei muito, mais esse Gó de cumpade Cazuza eu prantei foi quato roça de mandioca, quando uma dava ponto, tirava, e ficava boa, partia mais ele, eu fazia farinha, tirava goma, tirava puba.

Desse modo, das facas à lenha, do raspar ao prensar, do lavar ao triturar, do esfarelar ao torrar, bem assim nesse compasso, se evidencia a divisão sexual do trabalho, pois para aquecer a mandioca ao som da lenha, na fornalha, o "fazer-farinha", ou a chamada "farinhada", requer que, de início, se divida entre homens e mulheres as funções que moldam o comportamento e definem os contornos das tarefas para o processamento da mandioca na Casa de farinha. Essa forma de organização produtiva é considerada por Conceição (1981) e pelo folclorista brasileiro Cascudo (s.d.) como indício da contribuição indígena na formação da história brasileira, mas na linha do tempo instiga a vários estudos, principalmente no que tange a sobrevivência do seu estilo de produção, atrelado aos desafios inerentes a este tempo que conclama mudanças e/ou adaptações.

A moradora do Povoado de Itaipu, Dona Esmeralda, conta que, além de raspar a mandioca, realizava o trabalho de plantar como meeira com o dono da terra, pois não possuía terra para plantar. Dona Atila, uma senhora de 80 anos, tem recordações do tempo em que trabalhou em Casas de farinha nesse mesmo povoado, ao falar de como era o trabalho, diz que:

[...] fazia rapar mandioca, cessar massa, ai tudo que foi dando os trabai das Casa de farinha, trabaiei nove meis fazeno farinha. Lá ne Jambrim a mandioca era lavada e era a motor, tinha um giralzão, a farinha que eles fazia, eles vendia pra fora que era muita farinha. Nois mesmo nunca teve roça não, trabaiava era no macaco, era por semana. Aqui vinha caminhão 
eles vendia lá pra Conquista. (Entrevista realizada no dia 21 de Novembro de 2014, povoado de Itaipu, com Dona Atila, 80 anos.)

Observa-se na narrativa da mulher a alienação que produz a desumanização no trabalho, pela apropriação privada de um tempo de trabalho do trabalhador que vende a sua força de trabalho ao dono da terra.

Dona Atila, complementando seu olhar sobre seu trabalho nas plantações de mandioca e nas Casas de farinha, conta que:

Eu trabaiava ni Casa de farinha, ni roça, prantava maniva, prantei mais Demazim, prantei mais Fernando, pegava a mandioca e ia fazer farinha lá no Pau Ferro, na casa de cumpade Cazuza, rancava um cado de mandioca, meus menino ia arrancar, já fazia a farinha, era assim. (Entrevista realizada no dia 11 de Abril de 2015, Dona Atila, 80 anos)

Nos últimos anos, as Casas de farinha vêm perdendo notoriedade quantitativa nas localidades citadas, em razão de vários fatores, entre os quais, envelhecimento dos antigos proprietários e consequente aposentadoria; variabilidade do preço da farinha no mercado; ausência de mão de obra; dificuldade de sucessão do empreendimento para os mais jovens; o que levou aos pequenos agricultores a fecharem suas Casas de farinha e/ou reduzirem a fabricação, porém verifica-se que essa tradição ainda permanece viva na memória dos moradores e adjetiva a região e seus hábitos alimentares.

Verifica-se que a memória da tradição de uma comunidade permanece nas experiências educativas dos seus habitantes, enquanto os mesmos estiverem vivos:

[...] as suas técnicas, a suas histórias e a sua identidade coletivasurge como algo que sempre foi assim. Mas isso é apenas uma aparência, resultado do contínuo esborratar que acompanha a transformação da memória. O processo de transformação numa comunidade agrária tradicional pode ser lento; apesar disso, essas comunidades não ficam fora da história (FENTRESS e WICKHAM, 1992, p. 241).

Os grupos familiares de uma comunidade rural busca preservar seus significados, os quais resultam em tradições. Mas ao longo de um processo histórico, as novas técnicas promovem mudanças nas relações sociais e no espaço, e, por sua vez, o modo de vivência dos grupos precisam se adequar às mudanças, mesmo que possam manter as tradições de outrora, por intermédio da memória coletiva, plausível testemunha do passado vivenciado por tais grupos. Mesmo que muitas tradições sejam extintas, a memória coletiva propagada pelos moradores persiste enquanto os componentes dos grupos estiverem vivos, nos lembra Amaral (2016).

Por fim, nota-se que são as Casas de Farinha, e não, indústrias ou fábricas, que ainda subsistem na discussão exposta. A prática da "farinhada" não é apenas o resultado 
final de um sistema produtivo, ela vai além, alberga vínculos familiares na sua execução e particularidades que lhe faz específica, e que instiga estudo e reflexões.

\section{Considerações Finais}

Considerando o objetivo que norteou o presente estudo, pode-se verificar que as Casas de farinha constituem elementos de comunidades tradicionais, refletem muito dos atributos históricos que fundamentaram a sua edificação, entre eles: produção artesanal, laços familiares, socialização de saberes, divisão sexual do trabalho, a produção como construção social de um grupo.

Assim sendo, nota-se um forte alinhamento entre o trabalho e educação, estabelecendo entre ambos um campo de experiências educativas, posto que as práticas de ofício, ainda que não prevalecentes nos dias atuais, em função da diminuição das Casas de farinha nas comunidades, se fazem fortes e pautam relatos nas memórias dos moradores das referidas comunidades.

Considera-se que os resultados aferidos pelo estudo permitem reforçar alguns elementos característicos das comunidades tradicionais como: organização social particular, relação com a natureza e uso deste espaço para reprodução da condição de vida e utilizam conhecimentos específicos através da práxis, transmitidos pela tradição, onde a socialização de saberes (educação); vínculos familiares, relações de gênero (divisão do trabalho entre homens e mulheres) fortalecem esta construção de identidade.

Finalizando, vale ressaltar que ao mesmo tempo em que as Casas de farinha assumem esse papel libertador nas trocas de experiências educativas, produzem, também, a desumanização de mulheres, homens e crianças pela submissão a precárias condições de trabalho e acesso a bens materiais, sociais, culturais e econômicos.

\section{Referências}

ALGRANTI, Leila M. Famílias e vida doméstica. In: NOVAIS, Fernando A. (coord.) SOUZA, Laura Mello e (org.). História da vida privada no Brasil: cotidiano e vida privada na América portuguesa. Coleção História da Vida Privada no Brasil. v. 1. São Paulo: Companhia das Letras, 1997.

ALVES, Ana Elizabeth S. Divisão sexual do trabalho: a separação da produção do espaço reprodutivo da família. Trab. Educ. Saúde. Rio de Janeiro, v.11 n.2, p 271-289, maio/ago, 2013.

ALVES, Ana Elizabeth S.; CAVALCANTI JR, Manoel N.; SANTOS, Marisa O.; AMARAL, Urânia T. EXPOSIÇÃO: CASAS DE FARINHA. Grupo de estudos e pesquisas: História, Trabalho e Educação. XII Colóquio Nacional e V Colóquio Internacional do Museu 
Pedagógico "Estado, Política e Sociedade: está o mundo de ponta-cabeça?". Vitória da Conquista, BA: UESB, 2017.

AMARAL, Urânia T. Memória e Mobilidade do Trabalho no povoado de Itaipu, Município de Vitória da Conquista-BA. 2016, 116p. Dissertação Mestrado em Memória: Linguagem e Sociedade. Programa de Pós-graduação em Memória: Linguagem e Sociedade. Universidade Estadual do Sudoeste da Bahia.

BRASIL. Decreto 6.040 de 7 de fevereiro de 2007. Disponível em <http://www.planalto.gov.br/ccivil 03/ ato2007-2010/2007/decreto/d6040.htm>, acessado em 23 de dezembro de 2017.

CASCUDO, Câmara. História da Alimentação no Brasil. Vol. 1. 2 ${ }^{\mathrm{a}}$ ed. Belo Horizonte: Itatiaia; São Paulo: Edusp, 1983b.

, Luis da Câmara. Dicionário do folclore brasileiro. Rio de Janeiro. Ediouro, $\mathrm{s} / \mathrm{d}$.

CONCEIÇÃO, Antônio J. A mandioca. São Paulo: Nobel, 1981.

FERREIRA, Aurélio Buarque de $\mathrm{H}$. Novo dicionário da língua portuguesa. Rio de janeiro: Editora nova fronteira, 1975.

HALBWACHS, Maurice. A memória coletiva. São Paulo: Vértice, editora revista dos tribunais, 1990.

HIRATA, Helena. KERGOAT, Danièle. Novas configurações da divisão sexual do trabalho. Tradução: Fátima Murad. Cadernos de Pesquisa, v.37, p.595-609, set/dez 207.

HOBSBAWN, Eric. J. A era das revoluções. 1789-1848; 16. Ed. Tradução de Maria Tereza L. Teixeira e Marcos Penchel. Rio de Janeiro: Paz e Terra, 2002.

IBGE - INSTITUTO BRASILEIRO DE GEOGRAFIA E ESTATÍSTICA. CENSO 2010. Disponível em: < http/www.ibge.gov.br.htm>. Acesso em: 08 de dezembro 2017.

MARTINS, Gilberto de Andrade. Estudo de caso, uma estratégia de pesquisa. 2. Ed. São Paulo, Atlas, 2008.

MINAYO, Ma . Cecilia de S.(Org.) Pesquisa social: teoria, método e criatividade. 17 ed. Petrópolis, RJ: Vozes, 1994.

OLIVEIRA, Ivanilde Apoluceno de. Cartografias ribeirinhas. Saberes e Representações sobre práticas sociais cotidianas de Alfabetizando amazônicas. Belém: Eduepa, 2008, 2.ed.

PEDROZA, Manoela. A roça, a farinha e a venda: a produção de alimentos, mercado interno e pequenos produtores no Brasil colonial. In: FRAGOSO, João; GOUVÊA, Maria de Fátima (org.). Coleção O Brasil Colonial: 1720-1821. v. 3. Rio de Janeiro: Civilização Brasileira, 2014. 
SAMPAIO, Antônio Carlos Jucá de. Fluxos e refluxos mercantis: centros, periferias e diversidade regional. In: FRAGOSO, João; GOUVÊA, Maria de Fátima (org.). Coleção 0 Brasil Colonial: 1580-1720. v. 2. Rio de Janeiro: Civilização Brasileira, 2014.

SANTOS, Marisa O. Sistema de produção em Casas de farinha: Uma leitura descritiva na comunidade de Campinhos - Vitória da Conquista (BA), 2007. 115p. Dissertação Mestrado em Desenvolvimento Regional e Meio Ambiente - Programa Regional de Pósgraduação em Desenvolvimento Regional e Meio Ambiente, Universidade Estadual de Santa Cruz.

SAVIANI, Dermeval. Trabalho e educação: fundamentos ontológicos e históricos. Revista Brasileira de Educação. V 12. N34. Jan/abr,2007

SHARPE, Jim. A história vista de baixo. In: BURKE, Peter (org.). A Escrita da História. São Paulo: UNESP, 1992 (p. 39-62).

SIMMEL, Georg. Questões fundamentais da sociologia: individuo e sociedade. Tradução Pedro Caldas. Rio de Janeiro: Ed. Jorge Zahar, 2006.

SOUZA, Laura Mello e. Formas provisórias de existência: a vida cotidiana nos caminhos, nas fronteiras e nas fortificações. In: NOVAIS, Fernando A. (coord.) SOUZA, Laura Mello e (org.). História da vida privada no Brasil: cotidiano e vida privada na América portuguesa. Coleção História da Vida Privada no Brasil. v. 1. São Paulo: Companhia das Letras, 1997.

TUFANO, Douglas. A carta de Pero Vaz de Caminha. Comentada e ilustrada. São Paulo: Moderna, 1999. 